
\title{
$\angle S$ Research Square \\ "Face" and family preference of job matters: Association between Face need, lock-in job and burnout among high-tech company workers in Taiwan
}

\section{Feng-jen Tsai}

Taipei Medical University

Ruey-Yu Chen ( $\square$ rueyyu535@gmail.com )

https://orcid.org/0000-0001-9381-1117

Hsin-Jou Chen

Taipei Medical University

\section{Research article}

Keywords: Lock-in job, burnout, social-oriented job preference, face, Taiwan

Posted Date: July 30th, 2020

DOI: https://doi.org/10.21203/rs.3.rs-39515/v1

License: (c) (1) This work is licensed under a Creative Commons Attribution 4.0 International License.

Read Full License 


\section{Abstract \\ Background}

Studies on health impact of lock-in job are mainly conducted in western countries with theory based on the value of individualism. We argued that the social-oriented concern should be considered in workers' lock-in status in Chinese society.

\section{Methods}

Anonymous survey were conducted on 1102 workers of high-tech companies in Taiwan from October 2015 to January 2016 to assess their face need, lock-in status of job and burnout. Except separate into 3 groups by lock-in score, participants were categorized by the conflict of preference of job between themselves and their family. Chi-square test, ANOVA test, Person correlation test and regression were applied.

\section{Results}

Among 1102 participants, $18 \%$ had job that they did not prefer but their family prefer. Participants with higher face need and higher lock-in status had significantly higher risk of developing personal and workrelated burnout. But the analysis using "lock-in Job for conflict of preference between themselves and their family" status showed more coherent result. Participants with job which "self not prefer but family do" had 2 times risk of having personal and work-related burnout $(\mathrm{OR}=2.03$ and 2.34). Participants with job which both themselves and their family not prefer had 4 times risk of having personal and workrelated burnout $(\mathrm{OR}=4.10$ and 4.17$)$.

\section{Conclusions}

Our study result indicated the importance to consider social-oriented job preference in lock-in status evaluation in Chinese culture. Workers' lock-in status as their preference conflicting with their family's preference showed significantly negative impact on their health.

\section{What This Paper Adds}

\section{What is already known about this subject?}

Lock-in status which referring to workers' non-preference toward his job is harmful to workers' well-being. However, those studies were conducted only in western countries with the theory based on the value of individualism. 


\section{What are the new findings?}

Different with individual-oriented approach of interacting with living environment (or life sphere) in western countries, individuals in eastern countries generally took the social-oriented approach to interact with their life sphere. Also, the concern of "face" is one of the important concepts in individuals' decision concerning the relationship with others in Chinese culture. This study argued the need to consider socialoriented job preference in lock-in studies. And the study result showed that participants' face need and lock-in status were significantly associated with their personal and work-related burnout. Participants with higher face need had significantly higher risk of developing personal and work-related burnout. Similarly, participants with higher lock-in status had significantly higher risk of developing personal and work-related burnout.

\section{How might this impact on policy or clinical practice in the foreseeable future?}

The study recommended a culture-sensitive policy in workplace mental health program. Also, there is further need to understand the impact of social-oriented job preference on job performance and workers' long-term health.

\section{Background}

Historically, "lock-in" among employee referred to a situation that workers have difficulty transiting to another "at least equally good" job in labor studies[1-3]. The key concept of such situation is the nonpreference toward one's job, so the worker not wanting to remain in the current workplace in the future[3]. To remain in the non-preferred job, despite wanting to change company or workplace is likely to cause strain on workers and lead to impaired well-being[2-5]. Though the study on health impact of lock-in job were comparatively rare, the studies showed that people in non-preferred jobs reported poor psychological well-being[2]. Recently, Stengard further added the element as "perceived employability" in being locked-in with the argument that revolving a situation of non-preferred occupation often requires a complete career re-orientation, which is difficult. Therefore, perceived employability played a role in lock-in status of employees. And their studies based on longitudinal design also showed the negative impact of lock-in status on well-being among workers [6, 7].

However, those studies were conducted only in western countries with the theory based on the value of individualism. Study suggested that though the benefit of voluntary job transition as increased salary or self-esteem were obvious, employees occasionally decided to stay in their current job despite the availability of other suitable jobs due to several reasons[8, 9]. Except the satisfaction of their current job, the fit between work and private life, social relations with co-workers were ever pointed out to be the reasons[10]. Those findings suggested the broader work-related context including factors that are more indirectly connected to the job, rather than work tasks themselves, could be an important reason for remaining in a job. 
Different with individual-oriented approach of interacting with living environment (or life sphere) in western countries, individuals in eastern countries generally took the social-oriented approach to interact with their life sphere [11-13]. Indigenized Chinese psychology-Kuo-shu Yang proposed a four-part theory of the Chinese self to explain how Chinese individual build their own identity and interact with others[14, 15]. He argued that the Chinese self is composed of both the individual-oriented and social-oriented self, with the latter further divided into the relationship-oriented, familistic (group)-oriented, and other-oriented self. According to the definition, "the individual-oriented self is a combination of a tendency toward high personal autonomy and low homonymy that emphasizes an individual's personal achievement, performance, uniqueness and autonomy"[16]. And "the social-oriented self is a combination of a tendency toward high homonymy (with the surrounding environment) and low personal autonomy, emphasizing that this type of self which attaches importance in order to maintain harmonious interpersonal relationships, accountability, and responsibility and requires appropriate personal behaviors such that individuals position themselves according to their relationship with others"[16]. As an individual grown in such a collectivist culture, concerns of family and others are fundamental in all kinds of individual decisions, including decision related to work.

The concern of "face" is one of the important concepts in individuals' decision concerning the relationship with others in Chinese culture[11, 17]. Different with the concept of "face" in the Western culture as politeness, it refers to a sociological concept which linked to the dignity, prestige and reputation that a person has in terms of their social relationships in Chinese culture[18, 19]. While job title and industry linked to the social recognition of workers in eastern culture, the decision of taking a job or transferring to another job is highly bounded with the concern of "face" of individuals[17]. In addition, Taiwan is a typical Chinese society which is strongly influenced by the traditional value of filial piety[20, 21]. Many Chinese parents consider the job and career of their adult child as an issue of face which representing their achievement in raising child[22]. So they will urge their adult child to take a job with better social reputation. With these strong cultural influences, we argued that the social-oriented concern should be considered in lock-in evaluation that the preference of job of individuals' family also played a role in workers' lock-in status in Chinese society. Therefore, we hypothesis that workers in Taiwan might take the job they do not prefer based on the concern of faces of themselves and their parents. And the conflict of personal preference and family preference toward one's job represent the lock-in status of individual, and leaded them to develop burnout syndrome.

In detail, our hypotheses are:

\section{Hypothesis 1}

The social-oriented job preference plays an important role in workers' lock-in status. And the lock-in status which workers' preference is conflicting with their family's preference will have negative impact on workers' health.

\section{Hypothesis 2}


Workers' face need is positively related to their lock-in status represented by workers' preference and the preference of workers' family. In other words, workers with higher face need have higher risk of being lockin job.

In Taiwan, work in high-technology industry is considered as fashion job with potential high salary and good career future[23]. And work in big company is considered as good job due to the possible job security and popular recognition among society, though the working condition including salary and work hours might sometimes worse than other smaller companies[24]. Therefore, we conducted the study on high-tech company workers.

\section{Methods}

We conducted an anonymous self-reported questionnaire survey on workers of 3 high-tech companies in Taiwan from October 2015 to January 2016 to assess their face need, lock-in status of job and burnout.

The questionnaire was delivered to 2341 workers and 1102 completed and returned their questionnaires surveys. The response rate is $47.07 \%$, and all of these questionnaires were included in the final analysis.

The research protocol was approved by the Institutional Review Board of Taipei Medical University (No. N201805098). And verbal consent was obtained before the survey.

\section{Measure}

\section{Independent variables}

Work-related individual characteristics, including job content (engineer, administrator and others), age, gender, work experience, education level, marital status, number of children, job level (administrative level or not), salary, and working hours per day were all collected for analysis.

\section{Lock-in status}

We used and modified the workplace preference scale of Stengard's lock-in questionnaire in the study [6, 7]. Workplace preference was measured by questions as "Is your current occupation the occupation you expected?"; "Is your current occupation the occupation you wish in the future?"; "Is the company you work today the company you expected?"; and "Is the company you work today the company you want to work in the future?"

We further added the social-oriented concern question of lock-in status as "Is your current occupation the occupation your family (parents, spouses and relatives) expected?" and "Is the company you work today the company your family expected?" The responses were evaluated with 4-point Likert-scale from $1=$ very much disagree to 4 = very much agree. 
Information of perceived employability used in Stengard's lock-in questionnaire was also collected for analysis.

\section{Face need}

For evaluating the concern of face, we used "face need questionnaire" developed by Chinese psychologist[25-27]. The Cronbach's avale of the questionnaire is 0.84 . The questionnaire of face covered 2 sub-items: (1) concern about self-face (14 items); and (2) concern about others' face (7 items). The responses were evaluated with 5 -point Likert-scale from $0=$ very much disagree to $5=$ very much agree. The higher scores represent the higher face need of participants.

Regarding evaluating the concern of self-face, participants were asked questions as "When someone criticizes me, it affects me more in public than in private", "During the discussion, I try not to ask questions because I may appear ignorant in front of others", "I will keep a low profile because I don't want to make mistakes in front of others", "Before I express my opinion in front of others, I will repair it first.", "I will degrade my abilities and achievements so that others will not have unrealistic expectations of me", "I will plan my words and actions carefully to reduce errors", "Before commenting on things, I will first say that I may not necessarily be correct", "When I touch others, I care about what they expect of me", "I feel hesitant to ask for assistance because I think my request will cause inconvenience to others", "I try not to do things that will cause others to notice me", "I don't criticize others because it makes them embarrassed", "Before I do things, I carefully observe the actions and actions of others", "I do not complain publicly, even if I have been treated unfairly" and "I try to make me behave like others in order to meet social standards". Regarding evaluating the concern about others' face, participants were asked questions as: "Before I do anything publicly, I prepare myself for any possible outcome"; "I like to use third parties to resolve disagreements between me and others"; "When discussing a problem, I try to let the other person know that I am not accusing him"; When someone criticizes me, I try to avoid that person "'; "When I make a mistake in front of everyone, I try to keep them from noticing the mistake"; "Even if I know someone is at fault, I am careful not to criticize him"; and "When someone embarrasses me, I try to ignore him".

\section{Burnout}

We use burnout as health outcome indicator in the study. The Chinese version of the 21 -item "Copenhagen Burnout Inventory" (C-CBI) was used to measure the three domains of burnout: personal burnout, work-related burnout and client-related burnout[28]. In this study, we only measured the personal (5 items) and work-related burnout (5 items) among workers. From the definition of the $\mathrm{CBI}$, personal burnout is "the degree of physical and psychological fatigue and exhaustion experienced by the person," work-related burnout is "the degree of physical and psychological fatigue and exhaustion that is perceived by the person as related to his/her work"[29]. The responses were evaluated with 5-point Likertscale from $0=$ never to $5=$ always.

\section{Data analysis}


We used two approaches to calculate the lock-in status of participants. The score of participants' preference and their family's preference of the job were summed up to be the lock-in scores. Then the lock-in scores were tertiled into 3 groups for analysis. We also categorized participants by the conflict of preference of job between themselves and their family as "lock-in Job for conflict of preference between themselves and their family" status. Participants were divided into 4 groups as "both prefer", "self-prefer but family not", "self not prefer but family do" and "both not prefer".

We adopted three different approaches in performing the analysis. For summary statistics, the Chi-square test was used to compare individual characteristics including age, gender, educational status, marital status, job content, work level, work year, working hours per day and company size by "lock-in Job for conflict of preference between themselves and their family" status. The ANOVA test was applied to compare the means of face need including concern of self-face and concern of others' face; burnout including personal and work-related burnout; and self-evaluated employability between "lock-in Job for conflict of preference between themselves and their family" status. Person correlation analysis is used to evaluate the association between Face need and lock-in status.

Personal burnout and work-related burnout were defined as dichotomized variables with cut-point as mean score. Logistic regression was then adopted to estimate the association between face need, lock-in status and burnout after adjusting for confounders. Variables which were significantly associated with personal and work-related burnout in bivariate analysis including age, gender, educational status, marriage status, job content, work year, working hour per day, company size and self-perceived employability were adjusted in the regression model. We also run the regression for evaluating the associations between face need, "lock-in job for conflict of preference between themselves and their family" status and burnout.

The odds ratios (OR) and its $95 \%$ confidence intervals (Cls) were also calculated. The significance level was set at 0.05. All analysis was performed using the software SPSS, Version 18.0.

\section{Results}

\section{Comparison of individual characteristics between "lock-in Job for conflict of preference between themselves and their family" status groups by chi-square test}

Comparison of individual characteristics between "lock-in Job for conflict of preference between themselves and their family" status groups by chi-square test were showed in Table 1. In general, majority of our participants single (57.17\%) male $(59.44 \%)$ aged 30 to 39 years old $(53.36 \%)$ with educational degree above college (97.83\%). Moreover, $68.78 \%$ of our participants were engineers without administrative position. While $48.55 \%$ of them only worked for less than 5 years, $54.72 \%$ of them worked over 40 hours per week. And $83.58 \%$ of them worked in big company with more than 500 employees.

Among 1102 participants, $18 \%$ had job that they did not prefer but their family prefer, and $9 \%$ of them had a job which both themselves and their family did not prefer. Educational status, marriage status and 
company size were significantly different between "lock-in Job for conflict of preference between themselves and their family" status groups. For educational level, the percentage of participants with educational level as master and above were highest in "self not prefer but family do" group (55.72\%), than in "both prefer" group (54.23\%), than in "self-prefer but family not" group (44.12\%), than in "both not prefer" group (41.84\%). For marriage status, the highest marriage rate is in "both prefer" group (43.56\%), than in "both not prefer" group (40.82\%), than in "self-prefer but family not" group (38.24\%), than in "self not prefer but family do" group (35.32\%). For the company size, the percentage of participants worked in big company was highest in "self not prefer but family do" group (88.56\%), than in "both prefer" group (84.92\%), than in "both not prefer" group (68.37\%), than in "self-prefer but family not" group (67.65\%). The other factors were not significantly different between groups.

\section{Comparison of face need, burnout and self-perceived employability between "lock-in Job for conflict of preference between themselves and their family" status groups by ANOVA}

Comparisons of face need, burnout and employability between "lock-in Job for conflict of preference between themselves and their family" status groups by ANOVA were showed in Table 2 . The face need including concern of self-face, concern of others' face; burnout including personal burnout and workrelated burnout, and self-perceived employability were all significantly different between groups. The face need was highest in "both prefer" group (70.7), than in "self not prefer but family do" group (70), than in "both non-prefer" group (67.59), than in "self-prefer but family not" group (66.68). The concern of selfface is highest in "both-prefer" group, than in "self not prefer but family do" group, than in "both not prefer" group, than in "self-prefer but family not" group. Differently, the mean of concern of others' face is highest in "self not prefer but family do" group, than in "both prefer" group, than in "both not prefer" group, than in "self-prefer but family not" group.

The personal burnout is highest in "both not prefer" group, than in "self not prefer but family do" group, than in "self-prefer but family not" group, than in "both prefer" group. Similarly, the work-related burnout is highest in in "both not prefer" group, than in "self not prefer but family do" group, than in "self-prefer but family not" group, than in "both prefer" group.

The self-perceived employability is highest in "both prefer" group, than in "self not prefer but family do" group, than in "both not prefer" group, than in "self-prefer but family not" group.

The Pearson correlation analysis showed that participants' face need is not correlated with their lock-in status evaluated by both approaches.

\section{Associations between face need, lock-in job status and burnout}

Associations between face need, lock-in job status and burnout by regression were showed in Table 3 . Workers' marriage status, job content, working hours per day and their Company size, self-perceived 
employability, face need and lock-in job status were all significantly associated with personal and workrelated burnout.

For model 1 which using tertiled lock-in scores for analysis, marriage status, job content, company size, face need and lock-in status were all significantly associated with personal burnout. Participants with marriage status as others (divorce or widowhood) and job content as others had significantly higher risk of developing personal burnout than single participants $(O R=10.93$ and $O R=1.83)$. Participants worked in big company had significantly lower risk of having personal burnout than participants worked in smaller size companies $(\mathrm{OR}=0.54)$. Importantly, participants with high face need had significantly higher risk of developing personal burnout $(\mathrm{OR}=1.91)$. Moreover, participants with high lock-in job status had significantly higher risk of having personal burnout $(O R=1.75)$. And participants with middle lock-in job status had 4 times risk of having personal burnout $(\mathrm{OR}=3.96)$.

For work-related burnout, participants worked in big company had significantly less chance of workrelated burnout $(\mathrm{OR}=0.23)$. Participants with high face need had significantly higher risk of developing work-related burnout $(\mathrm{OR}=1.68)$. Moreover, participants with high lock-in job status had significantly higher risk of having personal burnout $(O R=1.82)$. And participants with middle lock-in job status had 4 times risk of having personal burnout $(\mathrm{OR}=4.49)$.

For model 2 which using "lock-in Job for conflict of preference between themselves and their family" status for analysis, marriage status, job content, company size, face need and "lock-in Job for conflict of preference between themselves and their family" status were all significantly associated with personal burnout. Participants with marriage status as others (divorce or widowhood) and job content as others had significantly higher risk of developing personal burnout than single participants $(O R=10.01$ and $O R$ $=1.73$ ). Participants worked in big company had significantly lower risk of having personal burnout than participants worked in smaller size companies $(\mathrm{OR}=0.55)$. Participants with high face need had significantly higher risk of developing personal burnout $(\mathrm{OR}=1.88)$. Moreover, participants with "lock-in Job for conflict of preference between themselves and their family" status as "self not prefer but family do" had 2 times risk of having personal burnout $(O R=2.03)$. And participants with job which both themselves and their family not prefer had 4 times risk of having personal burnout than both prefer group $(\mathrm{OR}=4.10)$.

For work-related burnout, participants worked in big company had significantly less chance of workrelated burnout $(O R=0.25)$. Participants with high face need had significantly higher risk of developing work-related burnout $(\mathrm{OR}=1.62)$. Moreover, participants with "lock-in Job for conflict of preference between themselves and their family" status as "self not prefer but family do" had 2 times risk of having work-related burnout $(\mathrm{OR}=2.34)$. And participants with job which both not prefer had 4 times risk of having work-related burnout $(\mathrm{OR}=4.17)$.

\section{Discussion}


To our knowledge, this is the first study arguing the need to consider social-oriented job preference in lock-in studies. Also, this is the first study focusing on the impact of special concern in Chinese cultureface on lock-in status and burnout among workers. Our study result showed that participants' face need and lock-in status were significantly associated with their personal and work-related burnout. Participants with higher face need had significantly higher risk of developing personal and work-related burnout. Similarly, participants with higher lock-in status had significantly higher risk of developing personal and work-related burnout.

From study result, it is not surprising that participants in higher lock-in status showed significantly higher risk of developing personal and work-related burnout. But interestingly, participants with middle lock-in status had highest risk of developing personal and work-related burnout. Their risk is even higher than workers with high lock-in status. This phenomenon might be caused by the fact that two thirds of our participants whose preference is conflict with their family would located in middle lock-in group. The analysis using "lock-in Job for conflict of preference between themselves and their family" status showed more coherent result for the risk of developing burnout syndrome among workers. Participants with "lockin Job for conflict of preference between themselves and their family" status as "self not prefer but family do" had 2 times risk of having work-related burnout. And participants with job which both not prefer had 4 times risk of having work-related burnout. This result indicates that workers' preference towards their job played the most important role in protecting their health. Even if the worker has a high socioeconomic status job which everyone admires, if he does not like the job himself, his feeling of being trapped at work will lead him to develop burnout syndrome. Also, the result findings supported our argument that socialoriented concern should be considered in lock-in evaluation in Chinese society. This finding might also generalize to other Asian countries with

patriarchal culture.

Regarding face need, study result showed that participants with higher face need had significantly higher risk of having personal and work-related burnout. Though the correlation between face need and lock-in status is not found by Pearson correlation analysis, we found that workers stayed in job which "self-not prefer but family do" were the workers who had high face need. There were $18 \%$ participants in our study locked in the job which they do not prefer but their family preferred. While they were the group with highest concern of other's face, there is a high possibility that they stayed in the job they do not prefer in order to make their parents or families "having face". In other words, those workers which having high face need and high concern of other's face were locked in job due to the concern of face. And so, workers who had high face need showed significantly higher risk of developing personal and work-related burnout.

Interestingly, those participants (69.78\%) reported that both themselves and their family prefer their job also reported similarly high face need with the workers stayed in job which "self-not prefer but family do". Though the percentage of having marriage and the percentage of working in smaller company are higher in "both prefer" group, the social-economic background of those 2 groups was similar. The majority of 
those two groups were both single young male with educational level as master and above, working as engineers. In addition, nearly $50 \%$ of them had work experience less than 5 years. There might be a possibility that participants in "both prefer" group were actually self-convinced that they like the job because they felt proud about their good social-economic status and enjoyed the feeling of "having face" by themselves and their family. Further study is needed to understand the reason behind this phenomenon.

Several limitations were noted in the study. First, the response rate is comparatively low. While the nonresponse workers might be the workers with high work stress, we might under-reported the lock-in status among high-tech company workers. Second, relationships could only be considered as associations rather than causal due to the cross-sectional design. Third, we might not be able to rule out the report bias due to the study design as self-report.

\section{Conclusion}

In conclusion, our study result indicated the importance to consider social-oriented job preference in lockin status evaluation in Chinese society. We found that participants' face need and lock-in status were significantly associated with their personal and work-related burnout. Participants with higher face need had significantly higher risk of developing personal and work-related burnout. And workers' lock-in status as their preference conflicting with their family's preference showed significantly negative impact on workers' health. Further studies are recommended to understand the impact of social-oriented job preference on job performance and workers' long-term health.

\section{Abbreviations}

High-tech

High technology

$\mathrm{CBI}$

Copenhagen Burnout Inventory

OR

odds ratios

Cls

confidence intervals

\section{Declarations}

\section{Ethics approval and consent to participate}

The research protocol was approved by the Institutional Review Board of Taipei Medical University (No. N201805098). And verbal consent was obtained before the survey. 


\section{Consent for publication}

Not applicable

\section{Availability of data and materials}

The datasets used and/or analysed during the current study are available from the corresponding author on reasonable request.

\section{Competing interests}

The authors declare they have no competing interests.

\section{Funding}

This study was funded by the Health Promotion Administration, Ministry of Health and Welfare, R.O.C. (Taiwan). The funder did not involve in the study design and the process of the study.

\section{Authors' contributions}

FJT carried out the design of the study, perform the statistics and drafted the manuscript. RUC participated in the design of the study, data collection and the drafting of the manuscript. HJC participated in the design of the study, data collection and the analysis of the data. All authors have read and approved the manuscript.

\section{Acknowledgements}

Not applicable

\section{References}

1. Greenhaus JH, Callanan GA. Career dynamics. In: Handbook of psychology: Industrial and organizational psychology, Vol12, 2nd ed. ed. Hoboken: John Wiley \& Sons Inc; 2013: pp. 560-92.

2. Aronsson G, Goransson S. Permanent employment but not in a preferred occupation: psychological and medical aspects, research implications. J Occup Health Psychol. 1999;4(2):152-63.

3. Fouad NA, Bynner J. Work transitions. Am Psychol. 2008;63(4):241-51.

4. Muhonen T. Feeling double locked-in at work: Implications for health and job satisfaction among municipal employees. Work (Reading Mass). 2010;37(2):199-204.

5. Fahlen G, Goine H, Edlund C, Arrelov B, Knutsson A, Peter R. Effort-reward imbalance, "locked in" at work, and long-term sick leave. Int Arch Occup Environ Health. 2009;82(2):191-7. 
6. Stengård J, Bernhard-Oettel C, Berntson E, Leineweber C, Aronsson G. Stuck in a job: being "locked-in" or at risk of becoming locked-in at the workplace and well-being over time. Work Stress. 2016;30(2):152-72.

7. Stengård J, Berntson E, Leineweber C, Bernhard-Oettel C. Who Gets Stuck in Their Workplaces? The Role of Matching Factors, between Individual and Job, and Demographics in Predicting Being Locked In. Scandinavian Journal of Work and Organizational Psychology 2019, 4.

8. Ng TWH, Sorensen KL, Eby LT, Feldman DC. Determinants of job mobility: A theoretical integration and extension. Journal of Occupational Organizational Psychology. 2007;80(3):363-86.

9. Ng TWH, Feldman DC. Organizational embeddedness and occupational embeddedness across career stages. J Vocat Behav. 2007;70(2):336-51.

10. Mitchell TR, Holtom BC, Lee TW, Sablynski CJ, Erez M. Why People Stay: Using Job Embeddedness to Predict Voluntary Turnover. Acad Manag J. 2001;44(6):1102-21.

11. Hwang k-k. Face and Favor: The Chinese Power Game. Am J Sociol. 1987;92:944-74.

12. Yang K-S. Monocultural and cross-cultural indigenous approaches: The royal road to the development of a balanced global psychology. Asian Journal of Social Psychology - ASIAN J SOC PSYCHOL. 2000;3:241-63.

13. Yang K-S. Social Orientation and Individual Modernity among Chinese Students in Taiwan. The Journal of Social Psychology. 1981;113(2):159-70.

14. Yang KS, Lu L. Social- and individual-oriented self-actualizers: Conceptual analysis and empirical assessment of their psychological characteristics. Indigenous Psychological Research in Chinese Societies. 2005;23:71-143.

15. Yang KS. Chinese social orientation: an integrative analysis. Chinese Societies and Mental Health 1995:19-39.

16. Yang KS. A Theoretical and Empirical Analysis of the Chinese Self from the Perspective of Social and Individual Orientation. Indigenous Psychological Research in Chinese Societies 2004(22):11-80.

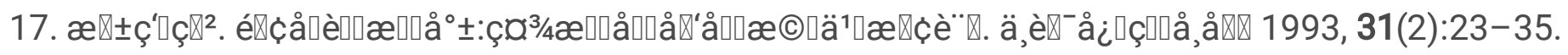

18. Han K-H. The Feeling of "Face" in Confucian Society: From a Perspective of Psychosocial Equilibrium. Front Psychol. 2016;7:1055-5.

19. Kim JY, Nam SH. The Concept and Dynamics of Face: Implications for Organizational Behavior in Asia. Organ Sci. 1998;9(4):522-34.

20. Yi C-c, Lin J-p. Types of Relations between Adult Children and Elderly Parents in Taiwan: Mechanisms Accounting for Various Relational Types. Journal of Comparative Family Studies. 2009;40(2):305-24.

21. Coombs LC, Sun T-H. Family composition preferences in a developing culture: The case of Taiwan, 1973. Population Studies. 1978;32(1):43-64.

22. Chu CR-L: Family Values and Parent-Child Interaction in Taiwan. In: The Family and Social Change in Chinese Societies. edn. Edited by Poston JDL, Yang WS, Farris DN. Dordrecht: Springer 
Netherlands; 2014: 177-193.

\section{Investigate the best tech industries in the minds of office workers}

[https://www.1111.com.tw/news/surveyns/122264/].

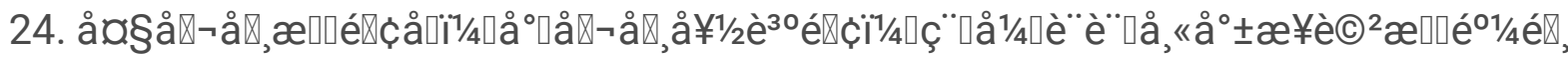

[https://kknews.cc/zh-tw/career/ygoe9qn.html].

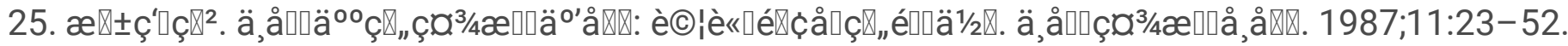

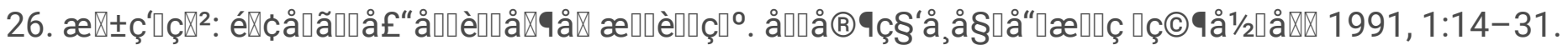

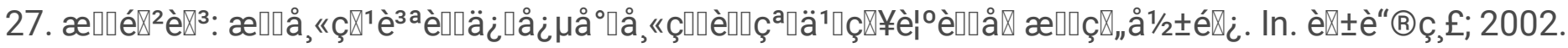

28. Yeh W-Y, Cheng Y, Chen C-J, Hu P-Y, Kristensen T. Psychometric properties of the Chinese version of Copenhagen Burnout Inventory among employees in two companies in Taiwan. Int J Behav Med. 2007;14:126-33.

29. Kristensen TS, Borritz M, Villadsen E, Christensen KB. The Copenhagen Burnout Inventory: A new tool for the assessment of burnout. Work Stress. 2005;19(3):192-207.

\section{Tables}

Table 1. Coaparison of Individual characteristics between Lock-in iob for confliet between theaselves and familv oreference starus by chi-sauare test

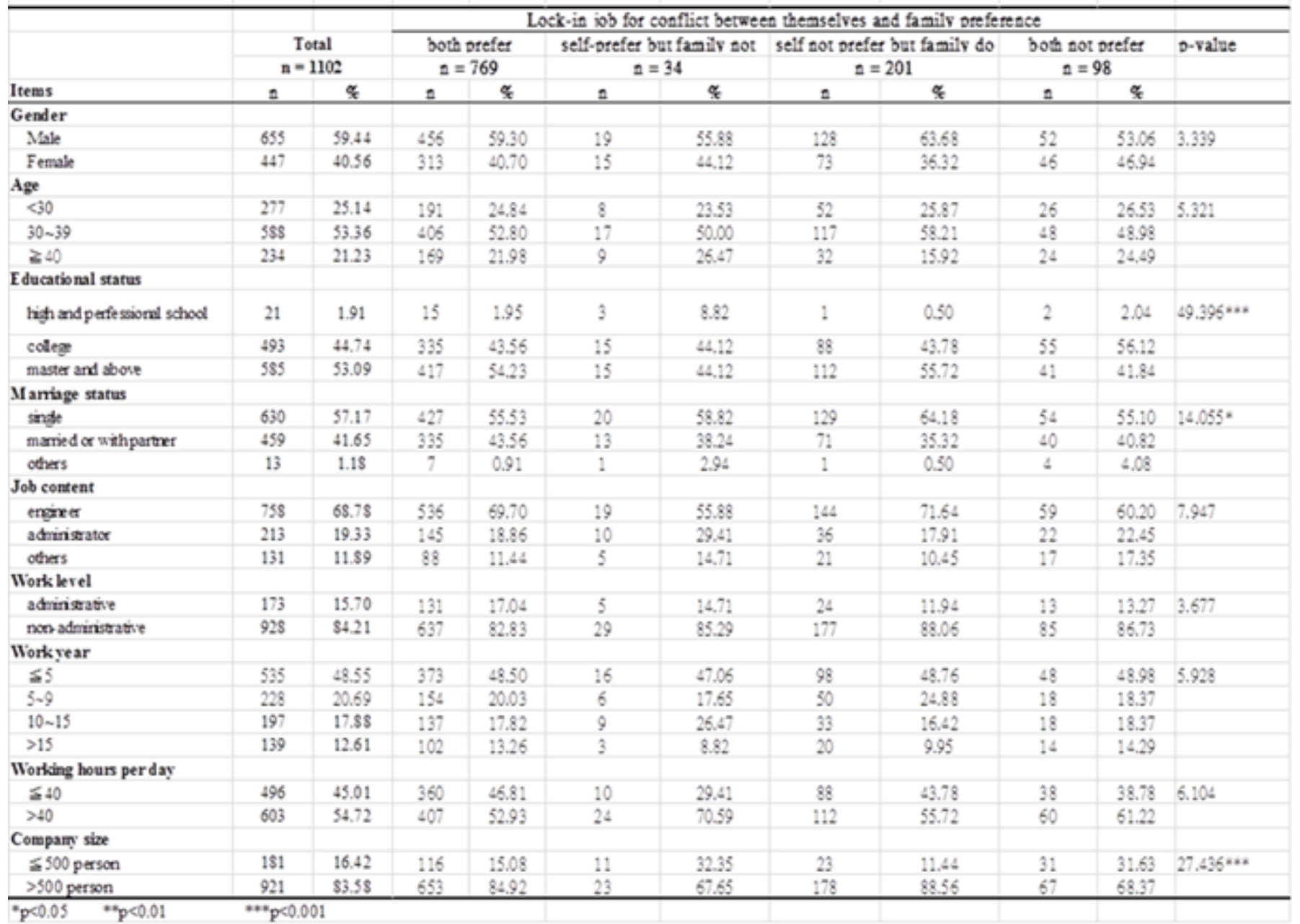


Table 2. Comparisons of face need, burnout and employability between Lock-in job for conflict between themselves and family preference status by ANOVA

\begin{tabular}{|c|c|c|c|c|}
\hline & \multicolumn{4}{|c|}{ Lock-in job for conflict between themselves and family preference } \\
\hline & both prefer & self-prefer but family not & self not prefer but family do & both not prefer \\
\hline & $\mathrm{n}=769$ & $\mathrm{n}=34$ & $\mathrm{n}=201$ & $\mathrm{n}=98$ \\
\hline & mean $(\mathrm{SD})$ & mean $(\mathrm{SD})$ & mean $(\mathrm{SD})$ & mean $(\mathrm{SD})$ \\
\hline Face need & $70.07(8.36)$ & $66.68(7.43)$ & $70(7.56)$ & $67.59(8.51)^{* *}$ \\
\hline self-face & $46.65(5.93)$ & $44.5(6.38)$ & $46.41(5.70)$ & $45.03(6.38) *$ \\
\hline others' face & $23.46(3.07)$ & $22.18(3.04)$ & $23.58(2.74)$ & $22.56(3.04)^{* *}$ \\
\hline \multicolumn{5}{|l|}{ Burnout } \\
\hline Work Bumout & $30.76(16.93)$ & $33.68(20.63)$ & $38.83(17.77)$ & $46.43(20.63)^{* * *}$ \\
\hline Personal bumout & $35.41(16.83)$ & $39.26(21.79)$ & $42.49(17.08)$ & $49.95(21.79)^{* * *}$ \\
\hline Self-perceived Employability & $2.75(0.68)$ & $2.47(0.78)$ & $2.63(0.77)$ & $2.49(0.78) * * *$ \\
\hline${ }^{*} \mathrm{p}<0.05 \quad{ }^{* *} \mathrm{p}<0.01$ & $p<0.001$ & & & \\
\hline
\end{tabular}


Table 3. Associations between face need, lock-in job and burnout

\begin{tabular}{|c|c|c|c|c|}
\hline \multirow[b]{2}{*}{ Items } & \multicolumn{2}{|c|}{ Model 1 } & \multicolumn{2}{|c|}{ Model 2} \\
\hline & Personal burnout & Work-related burnout & Personal burnout & Work-related burnout \\
\hline & ORs $(95 \% \mathrm{CI})$ & ORs $(95 \% \mathrm{CI})$ & ORs $(95 \% \mathrm{CI})$ & ORs $(95 \%$ CI $)$ \\
\hline \multicolumn{5}{|l|}{ Geader } \\
\hline Female & 1 & 1 & 1 & 1 \\
\hline Male & $1.31(0.97-1.77)$ & $1.36(1.00-1.84)$ & $1.30(0.96-1.76)$ & $1.35(1.00-1.84)$ \\
\hline \multicolumn{5}{|l|}{ Age } \\
\hline$<30$ & 1 & 1 & 1 & 1 \\
\hline $30 \sim 39$ & $1.14(0.79-1.64)$ & $1.26(0.87-1.83)$ & $1.17(0.81-1.69)$ & $1.29(0.90-1.87)$ \\
\hline$\geq 40$ & $0.99(0.58-1.68)$ & $0.94(0.55-1.60)$ & $1.04(0.61-1.76)$ & $0.97(0.57-1.67)$ \\
\hline \multicolumn{5}{|l|}{ Educational status } \\
\hline high and perfessional school & 1 & 1 & 1 & 1 \\
\hline college & $0.73(0.26-2.03)$ & $1.95(0.71-5.36)$ & $0.77(0.28-2.11)$ & $1.84(0.69 \cdot 4.94)$ \\
\hline master and above & $0.99(0.35-2.82)$ & $2.53(0.89-7.16)$ & $1.09(0.38-3.07)$ & $2.53(0.92-7.00)$ \\
\hline \multicolumn{5}{|l|}{ Marriage status } \\
\hline single & 1 & 1 & 1 & 1 \\
\hline married or with partner & $1.19(0.86-1.63)$ & $0.84(0.61-1.16)$ & $1.15(0.83-1.58)$ & $0.81(0.59-1.12)$ \\
\hline others & $10.93(1.33-89.96)^{*}$ & $3.67(0.73-18.53)$ & $10.01(1.20-83.25)^{*}$ & $3.38(0.67-17.12)$ \\
\hline \multicolumn{5}{|l|}{ Job content } \\
\hline engineer & 1 & 1 & 1 & 1 \\
\hline administrator & $1.19(0.80-1.79)$ & $1.00(0.66-1.51)$ & $1.24(0.83-1.85)$ & $1.06(0.71-1.60)$ \\
\hline others & $1.83(1.18-2.85)^{* *}$ & $1.47(0.93-2.31)$ & $1.73(1.11-2.69)^{*}$ & $1.38(0.88-2.17)$ \\
\hline \multicolumn{5}{|l|}{ work year } \\
\hline$\leq 5$ & 1 & 1 & 1 & 1 \\
\hline $5 \sim 9$ & $1.32(0.90-1.94)$ & $0.97(0.66-1.42)$ & $1.36(0.93-1.99)$ & $1.00(0.68-1.46)$ \\
\hline $10 \sim 15$ & $1.37(0.88-2.12)$ & $1.07(0.69-1.67)$ & $1.41(0.91-2.18)$ & $1.12(0.72-1.75)$ \\
\hline$>15$ & $1.42(0.83-2.42)$ & $1.29(0.74-2.22)$ & $1.47(0.86-2.50)$ & $1.28(0.75-2.20)$ \\
\hline \multicolumn{5}{|l|}{ working hours per day } \\
\hline$\leq 40$ & 1 & 1 & 1 & 1 \\
\hline$>40$ & $1.19(0.91-1.54)$ & $1.12(0.86-1.46)$ & $1.19(0.91-1.54)$ & $1.11(0.86-1.45)$ \\
\hline \multicolumn{5}{|l|}{ company size } \\
\hline$\leq 500$ person & 1 & 1 & 1 & 1 \\
\hline$>500$ person & $0.54(0.36-0.81)^{\cdots}$ & $0.23(0.15-0.36) \cdots$ & $0.55(0.37-0.83)^{\cdots}$ & $0.25(0.16-0.38)^{\cdots}$ \\
\hline \multicolumn{5}{|l|}{ Self-perceived Employability } \\
\hline high & 1 & 1 & 1 & 1 \\
\hline low & $1.20(0.92-1.57)$ & $1.10(0.84-1.44)$ & $1.18(0.90-1.54)$ & $1.09(0.83 \cdot 1.43)$ \\
\hline \multicolumn{5}{|l|}{ Face need } \\
\hline Low concern & 1 & 1 & 1 & 1 \\
\hline High concern & $1.91(1.47-2.49) * * *$ & $1.68(1.29-2.19) * * *$ & $1.88(1.45-2.45)^{* * *}$ & $1.62(1.25-2.11)^{* * *}$ \\
\hline \multicolumn{5}{|l|}{ lock-in Job status } \\
\hline low & 1 & 1 & \multirow{3}{*}{\multicolumn{2}{|c|}{ NA }} \\
\hline middle & $3.96(2.68-5.83)^{* \cdots *}$ & $4.49(3.02-6.66) \cdots$ & & \\
\hline high & $1.75(1.24-2.47)^{* *}$ & $1.82(1.29-2.58)^{* *}$ & & \\
\hline \multicolumn{5}{|c|}{$\begin{array}{l}\text { Lock-in job for conflict between } \\
\text { themselves and family preference }\end{array}$} \\
\hline both prefer & \multirow{4}{*}{\multicolumn{2}{|c|}{$\mathrm{NA}$}} & 1 & 1 \\
\hline self prefer but family not & & & $1.51(0.73-3.12)$ & $1.36(0.66-2.84)$ \\
\hline self not prefer but family do & & & $2.03(1.46-2.82)^{* \cdots *}$ & $2.34(1.67-3.26)^{* * *}$ \\
\hline both not prefer & & & $4.10(2.46-6.83) * * *$ & $4.17(2.49-6.98)^{* * *}$ \\
\hline${ }^{*} p<0.05 \quad * *_{p}<0.01$ & 0.001 & & & \\
\hline
\end{tabular}

